\title{
The influence of plant type on green roof rainfall retention
}

\author{
Article \\ Published Version \\ Creative Commons: Attribution 4.0 (CC-BY) \\ Open Access
}

Kemp, S., Hadley, P. and Blanusa, T. (2019) The influence of plant type on green roof rainfall retention. Urban Ecosystems, 22. pp. 355-366. ISSN 1083-8155 doi:

https://doi.org/10.1007/s11252-018-0822-2 Available at https://centaur.reading.ac.uk/80686/

It is advisable to refer to the publisher's version if you intend to cite from the work. See Guidance on citing.

To link to this article DOI: http://dx.doi.org/10.1007/s11252-018-0822-2

Publisher: Springer

All outputs in CentAUR are protected by Intellectual Property Rights law, including copyright law. Copyright and IPR is retained by the creators or other copyright holders. Terms and conditions for use of this material are defined in the End User Agreement.

\section{www.reading.ac.uk/centaur}

\section{CentAUR}

Central Archive at the University of Reading

Reading's research outputs online 


\title{
The influence of plant type on green roof rainfall retention
}

\author{
S. Kemp ${ }^{1} \cdot$ P. Hadley ${ }^{1} \cdot$ T. Blanuša ${ }^{1,2}$ (ID
}

(C) The Author(s) 2018

\begin{abstract}
Green roofs can mitigate the flood risk by reducing the volume of runoff through direct interception and subsequent evapotranspiration (ET), but the planting choices can influence the extent of this service. Glasshouse experiments were carried out in spring/ summer using simulated rainfall to compare the rainfall retention capacity of three physiologically active broadleaf species (Heuchera micrantha, Salvia officinalis and Stachys byzantina), which have previously shown to provide improved rooftop cooling, to an industry standard green roof species, Sedum spurium. Furthermore, the impact of varying ambient temperature and humidity conditions on the ability of these species to restore the substrate retention capacity through ET was also tested in a series of controlled-environment experiments simulating a range of potential UK summertime scenarios. Canopies alone retained up to $17 \%$ (Sedum) of the total rainfall in this study, with Salvia and Stachys also retaining in excess of 10\%, and can make a substantial contribution to rainfall retention on a green roof. Rainfall retention was also strongly correlated with total ET in the preceding $72 \mathrm{~h}\left(\mathrm{R}^{2}=0.94 ; P<0.001\right)$. Species with high ET rates (Salvia and Stachys) were able to provide the greatest stormwater management service (up to $72 \%$ retention due to ET component). Furthermore, species 'rankings', in terms of ET and thus restoration of substrate retention capacity, were the same in all simulated potential UK summertime temperature and relative humidity scenarios, indicating that 'superior' species will be able to provide the greatest stormwater management provision in all climatic conditions.
\end{abstract}

Keywords Evapotranspiration $\cdot$ Runoff $\cdot$ Salvia officinalis $\cdot$ Sedum $\cdot$ Simulated rainfall $\cdot$ Stachys byzantina

\section{Introduction}

In highly urbanised societies such as UK, already nearly $90 \%$ of the population reside in urban areas (Anon 2013). Development of cities, where soils and vegetation are replaced with impervious surfaces, leads to increases in incidents of surface flooding in urban areas (Perry and Nawaz 2008; Warhurst et al. 2014). Urban vegetation, including green roofs, can help to mitigate the flood risk by delaying and reducing the volume of runoff (Carter and Rasmussen 2006; Speak et al. 2013), with green roofs being able to retain up to $100 \%$ of the rainfall in individual storm events (Stovin et al. 2012).

Electronic supplementary material The online version of this article (https://doi.org/10.1007/s11252-018-0822-2) contains supplementary material, which is available to authorized users.

T. Blanuša

tijanablanusa@rhs.org.uk

1 School of Agriculture, Policy and Development, University of Reading, Reading, UK

2 Plant Sciences Department, Royal Horticultural Society, Garden Wisley, Woking GU23 6QB, UK
The main mechanisms through which vegetation on green roofs provides stormwater management are direct interception on plant canopies during rainfall, infiltration and storage of water in the substrate, and subsequent evapotranspiration (ET) from the green roof during dry periods (Stovin et al. 2012). Previous studies have identified several key factors influencing the retention performance of a green roof, including properties of the roof itself (e.g. slope; Getter et al. 2007), climatic and weather conditions (air temperature and humidity, net radiation, wind speed; Sims et al. 2016), characteristics of individual rainfall events (intensity, depth, duration; Stovin et al. 2012), and the substrate and vegetation types (Beecham and Razzaghmanesh 2015; Brandão et al. 2017).

The substrate of a green roof has frequently been acknowledged as the most important store of water (VanWoert et al. 2005). Retention of rainfall by a green roof has therefore been shown to depend on substrate characteristics, such as the type, depth and age of substrate (Mentens et al. 2006; Getter et al. 2007), and its properties, including water-holding capacity, porosity and antecedent substrate moisture content (SMC) (Stovin et al. 2015). Based on these factors, the substrate can retain a finite maximum volume of water during a rainfall event (defined as the substrate's retention capacity), after 
which any further water added will become runoff (Sims et al. 2016). Water stored in the substrate is subsequently lost from the green roof through ET, thus restoring the water retention capacity of the green roof following a rainfall event and allowing a greater volume of water to be retained by the roof in subsequent storms (Poë et al. 2015).

Vegetation, however, significantly increases the water retention capacity of a green roof compared to bare substrate alone (Voyde et al. 2010a), mainly as a result of the additional contribution of plant transpiration to total ET. Several studies also investigated differences in rainfall retention between different plant communities on green roofs (Nagase and Dunnett 2012; Whittinghill et al. 2015; Szota et al. 2017; Raimondo et al. 2015), suggesting that vegetation choice can influence the stormwater management capabilities of green roofs. Indeed, plant characteristics such as canopy structure, size and density, leaf morphology and root structure are thought to influence the capacity of particular species for direct interception (Nagase and Dunnett 2012; Lundholm et al. 2010; Aloisio et al. 2016).

The contribution of interception to long-term rainfall retention performance is, however, generally considered minor compared to the role of the vegetation in restoring substrate retention capacity through ET (Stovin et al. 2015). Evapotranspiration significantly influences the stormwater retention capacity, and thus the hydrological performance, of green roofs (Berretta et al. 2014). Due to the harsh environmental conditions typically experienced on green roofs, planting choices have traditionally been based on survival without irrigation, and hence species that are able to withstand substrate moisture deficits (i.e. succulents such as Sedum) are frequently used (Rayner et al. 2016). Likewise, the majority of green roof rainfall retention studies use succulent species or those with low water use rates (Starry et al. 2016; Berretta et al. 2014; Poë et al. 2015; Soulis et al. 2017). Using plants with inherently low ET rates will restrict the restoration of substrate retention capacity; Sedums have typically been found to provide lower rainfall retention due to their low ET rates (Whittinghill et al. 2015; Dunnett et al. 2008). Some recent research suggests however that drought-avoiding, low water-use plants, can also support rainfall retention on green roofs (Szota et al. 2017; Lundholm et al. 2010) and that Sedum species differ up to $20 \%$ in the rates of ET (Starry et al. 2016), so the story is clearly more nuanced and will be dependent on the local climatic circumstances. In principle though, species with significantly higher ET rates than Sedum will likely restore the substrate's water retention capacity faster and to a greater extent in dry periods between storms, so the rainfall retention is likely to improve in subsequent rainfall events.

In the UK, where average annual rainfall is high (between 600 and $3000 \mathrm{~mm}$; Met Office 2017) and where even summertime rainfall in the warmest south-eastern region can reach
$80 \mathrm{~mm}$ per month (Met Office 2017), choosing high ET species for green roofs would be plausible and advantageous. The substrate rainfall retention capacity could be restored quickly with these species as a result of their consistently high ET rates. Even if such species were implemented, a question remains whether 'superior' performers (i.e. those able to restore the substrate's rainfall retention capacity fastest and to the greatest extent due to high ET rates) remain 'superior' in a range of possible summertime temperature and humidity conditions (e.g. is there and advantage of having high ET species when the summer is humid and cool?). The main climatic parameters influencing ET are solar radiation, air temperature and humidity, and wind speed (Allen et al. 1998). Only a few studies have examined the influence of these climatic variables on the ET rates of green roof species (Berretta et al. 2014; Poë et al. 2015; Sims et al. 2016), especially whilst keeping all other factors constant (e.g. vegetation type, substrate type and depth, season and duration of study). These studies typically observed greater ET in summer compared to spring conditions (Berretta et al. 2014; Poë et al. 2015; Elliott et al. 2016) and in dry compared to humid climates (Sims et al. 2016), resulting from higher vapour pressure deficit (VPD) in warm and dry conditions driving faster ET. Indeed, in a study with identical green roofs located in different climatic regions in Canada (Sims et al. (2016)) found that, despite similar rainfall totals, overall retention was significantly higher on the green roof in the semi-arid climate $(75.2 \%)$ compared to the roof in the maritime climate $(43.4 \%)$. This was largely as a result of higher ET between storms on the roof in a semi-arid climate resulting in greater restoration of substrate retention capacity (Sims et al. 2016).

The objectives of our study were therefore:

i. To investigate the impact of green roof plant species choice on rainfall retention, through a combination of canopy interception and restoration of substrate retention capacity (via ET);

ii. To investigate the impact of varying environmental conditions (air temperature and relative humidity in different combinations) on the ET rates of a range of traditional and 'alternative' green roof species, and thus their capacity to retain rainfall.

Since it has traditionally dominated green roof planting choices, Sedum sp. was used in this study to represent an industry standard green roof species. Three significantly more physiologically active broadleaf species (Heuchera micrantha 'Obsidian', Salvia officinalis and Stachys byzantina), shown in our previous studies to offer superior cooling benefits in the UK climate context compared to Sedum (Vaz Monteiro et al. 2017), were selected for comparison. All these 'alternative' species have inherently high ET rates, large canopies of different densities and with varying leaf traits (presence or 
absence of leaf hairs, leaf size and leaf angles) which may aid, or hinder, rainfall retention.

\section{Materials and methods}

Experiments were carried out in late spring/early summer of 2015 and 2016 in the glasshouse and controlled environment laboratory at the University of Reading, UK.

\section{Plant material}

Three broadleaf species, Heuchera micrantha 'Obsidian' (large, glossy leaves forming a closed canopy with a relatively sparse understorey), Salvia officinalis (dense canopy with many 'layers' of leaves, which have rough surfaces and short hairs) and Stachys byzantina (full, dense canopy and long leaf hairs), were compared to Sedum spurium (small succulent leaves forming a dense, low-growing canopy) in all experiments. Heuchera plants were purchased as two-year-old plants in $2 \mathrm{~L}$ containers from Coblands Nursery (Tonbridge, UK), whilst all other species were propagated in-house.

\section{Experiment 1: The effect of vegetation type on green roofs' capacity to capture rainfall}

Experiments were carried out to quantify the volume of water that could be retained by plants with varying canopy characteristics and ET rates, using simulated rainfall to ensure consistency in the rainfall depth and intensity applied to each species. Experiments took place inside a ventilated glasshouse to avoid interference from natural precipitation in April 2016.

\section{Experimental set-up}

In February - March 2016, six replicates of each species were prepared, each planted in a $32 \mathrm{~L}$ plastic tray $(40 \times 60 \times 19 \mathrm{~cm}$, with drainage holes in the bottom) filled with $15 \mathrm{~cm}$ of peatbased compost (Vitax Ltd., Leicestershire, UK), the same substrate in which the plants were individually grown. The substrate had the following properties: $\mathrm{pH} 6$; air-filled porosity $55 \%$; substrate organic matter $75 \%$, and water-holding capacity $60 \%$. Six control trays of bare, unvegetated substrate were also prepared. As the purpose of the experiment was to compare plant species irrespective of the growing medium, and the experiment involved lifting and moving of large trays, a decision was made to use this lighter compost, rather than a conventional green roof one. To achieve full canopy cover over the tray, 3-4 two-year-old plants of Stachys, Sedum and Heuchera were planted per tray and six Salvia (propagated in autumn 2015) were planted per tray. The intention was to achieve a scenario of an aspirational green roof with $90-100 \%$ vegetation cover over the substrate (Fig. 1).

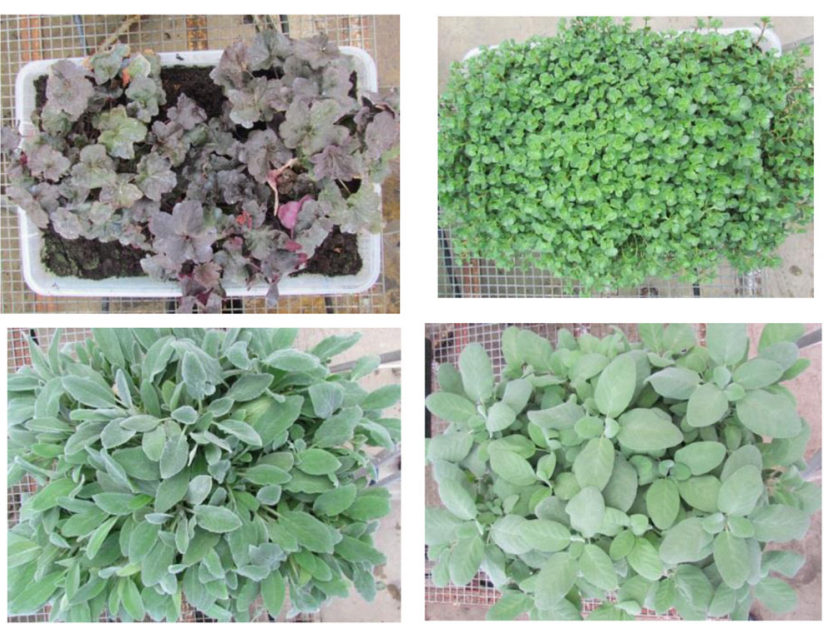

Fig. 1 The extent of vegetation cover for the studied species in trays clockwise from top left - Heuchera, Sedum, Stachys and Salvia

Two rainfall events were simulated for each tray, with varying antecedent substrate moisture conditions: 'saturated' and 'unsaturated'. 'Saturated' conditions were used to determine the contribution of canopy retention to overall rainfall retention by plants and substrate. 'Unsaturated' conditions were used to determine the contribution of ET to overall rainfall retention. To determine the volume of rainfall directly captured on the canopy, the substrate of all trays was watered to container capacity prior to rainfall application by submerging trays in water for $30 \mathrm{~min}$ and then leaving to drain for $2 \mathrm{~h}$. Thus, antecedent substrate moisture content (SMC) was high $\left(>0.550 \mathrm{~m}^{3} \mathrm{~m}^{-3}\right)$ and no further storage capacity was available in the substrate when rainfall was applied in these 'saturated' conditions. The second rainfall event was simulated three days after the first rainfall application, to quantify impact of ET on rainfall retention. The volume of water retained on the whole 'canopy/substrate complex' in 'unsaturated' conditions following a 72-h antecedent dry period was used as an indicator of the ET contribution to the retention process. ET rates of the chosen species differ, resulting in differing antecedent SMCs for each treatment at the onset of rainfall.

Mean environmental conditions in the glasshouse during the experiment were: day-time $(07.00-21.00) T=22{ }^{\circ} \mathrm{C}$, RH $56 \%$, mean radiation $256 \mathrm{~W} \mathrm{~m}^{-2}$; night-time (21.00-07.00) $T=19^{\circ} \mathrm{C}, \mathrm{RH} 68 \%$.

\section{Rainfall simulation}

To ensure that the characteristics of the simulated rainfall were consistent and similar to those of natural rainfall, a sprinkler system based on the design described by Iserloh et al. (2012) and designed in-house by an irrigation specialist at RHS Garden, Wisley, was used to simulate rainfall. Full details of the system, and how it was tested prior to the start of the experiments, are provided in Supplementary Material. Briefly, the system consisted of a Lechler 460,608 nozzle 
attached by a $2 \mathrm{~m}$ length of hosing to a flow control, consisting of a series of pressure gauges and filters, which was connected to the mains water supply by hosepipe. The nozzle, hosing and simulator were fastened to an L-shaped timber support $2.4 \mathrm{~m}$ high and $1 \mathrm{~m}$ across which was then secured to a metal pole in the glasshouse. During the experiments, trays were placed on a trolley $1.6 \mathrm{~m}$ below the nozzle for rainfall application and flow pressure was maintained at $15 \mathrm{kPa}$ to ensure consistent droplet production.

The simulator was tested extensively prior to the start of the experiments in order to determine suitable rainfall volumes and intensities and establish experimental procedures (Kemp 2018); also see Supplementary Material. The area below the nozzle was found to have the most consistent rainfall characteristics, with an intensity of $28 \mathrm{~mm} \mathrm{hr}^{-1}$, and was therefore chosen as the position for test trays during the experiments (Fig. 2). Mean rainfall applied was $9.3 \pm 0.3 \mathrm{~mm}$.

\section{Experimental procedure}

Trays were tested one at a time, with one tray of each treatment tested in turn to account for any possible changes in environmental conditions. Each tray was exposed to rainfall for $20 \mathrm{~min}$ to simulate a rainfall event of $9.3 \mathrm{~mm}$, considered medium-heavy in the classification system proposed by (Getter et al. 2007), and with a return period of $T=1.6$ years (Butler and Davies 2003). To measure runoff, each tray was placed inside a second, empty tray of the same dimensions before rainfall application (Fig. 2b), thus ensuring that no rainfall fell directly into the second tray and only runoff was collected.
Before rainfall application, each tray was weighed and antecedent SMC was measured using a WET sensor connected to a HH2 Moisture Meter (Delta-T Devices, Cambridge, UK), with five measurements per tray. After each simulated rainfall, trays were left to drain for $30 \mathrm{~min}$ (until runoff stopped) and then weighed again. The volume of water captured on the canopy or 'canopy/substrate complex' was taken to be the weight gain of each tray after rainfall application. The volume of water captured in the runoff tray was measured using measuring cylinders.

For three days following both rainfall applications, each tray was weighed and SMC was measured every $24 \mathrm{~h}$ to determine daily ET and thus the rate of restoration of substrate retention capacity. Trays remained in the glasshouse during this time and received no further irrigation. At the end of the experiments, a $15 \times 36 \mathrm{~cm}$ representative section of each planted tray was harvested for leaf area and biomass measurement. Shoots and roots were separated and roots were carefully washed, removing as much substrate as possible, before being dried in an oven at $70{ }^{\circ} \mathrm{C}$ for $72 \mathrm{~h}$ and weighed. Leaf area was measured using a leaf area meter with associated WinDIAS 3 Image Analysis System (Delta-T Devices, Cambridge, UK), and leaf area density (i.e. $\mathrm{cm}^{2}$ leaf area per $\mathrm{cm}^{3}$ of canopy volume) was calculated, as this parameter proved to be most descriptive of the canopy in our previous studies (data not shown).

\section{Experiment 2: The impact of varying temperature and humidity on plants' water use}

To examine how the ET rate of each species, and thus the rate of restoration of substrate retention capacity, varies in different
Fig. 2 The sprinkler rainfall simulator used in Experiment 1, showing the pressure regulators and filters connected to the nozzle (a) and the experimental setup of the simulator secured to an Lshaped timber support with a tray positioned below the nozzle on a trolley for testing (b)
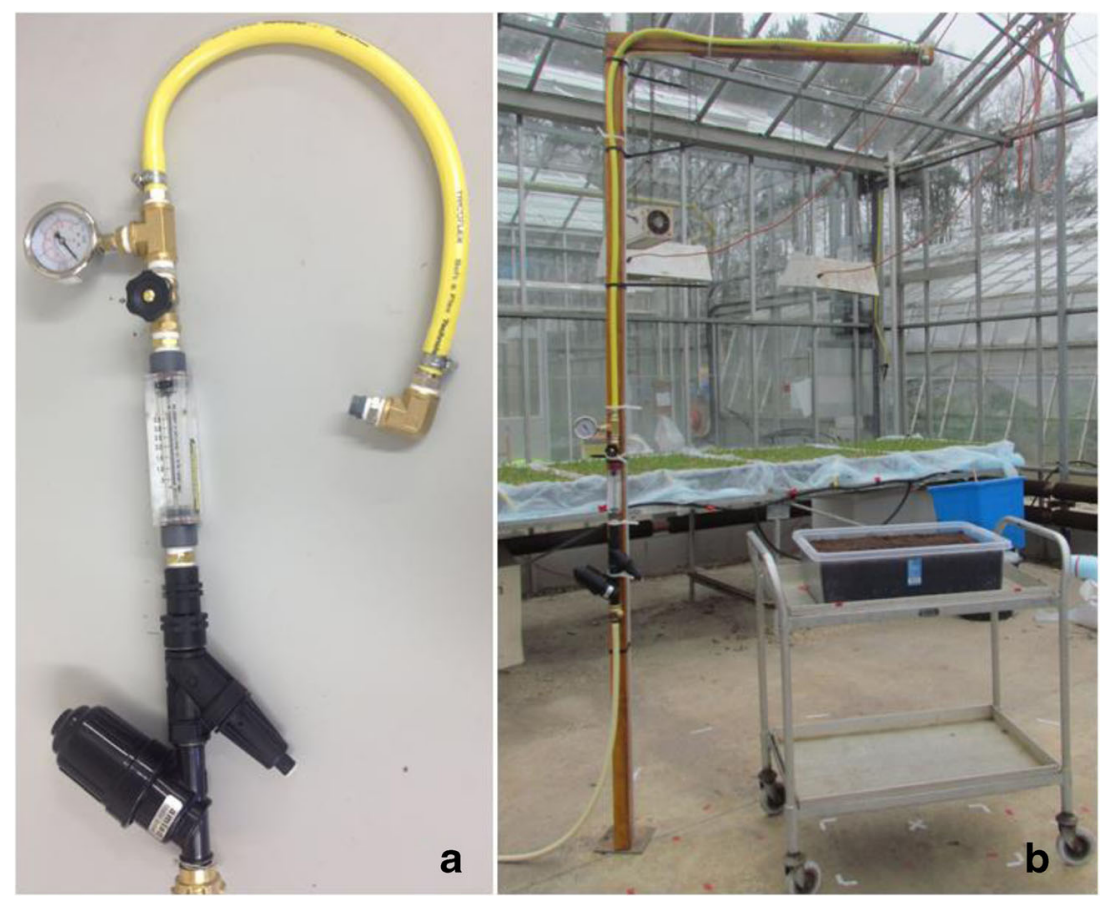
climatic conditions, a series of five consecutive trials, each with different temperature $(\mathrm{T})$ and relative humidity $(\mathrm{RH})$ conditions, took place between 9th March and 30th April 2015 in controlled environment (CE) cabinets.

\section{Experimental set-up}

In February 2015, individual two-year old plants of all species were planted into $2 \mathrm{~L}$ containers filled to a depth of $11 \mathrm{~cm}$ with an industry standard green roof substrate, Meadow Roof Medium (Vital Earth GB Ltd., Ashbourne, Derbyshire, UK), to replicate green roof conditions. The substrate had the following properties: $\mathrm{pH} 7.7$; air-filled porosity $48 \%$; soil organic matter $3.5 \%$; and water-holding capacity $26 \%$ (as defined by Vital Earth GB Ltd.). There were six replicates of each species and an additional six control containers with bare, unvegetated substrate.

\section{Temperature $(\mathrm{T})$ and relative humidity $(\mathrm{RH})$ treatments}

Five potential UK summertime T/RH scenarios were simulated using two Fisons 600G3/TL controlled environment growth cabinets (Fisons Scientific Apparatus, Loughborough, UK). A 16-h photoperiod (05:0021:00 h) was supplied by Phillips $40 \mathrm{~W}$ warm white fluorescent tubes, which provided a light intensity of $200 \mu \mathrm{mol} \mathrm{m} \mathrm{m}^{-2}$. While this is a maximum light intensity which can be generated in the cabinets, it is lower compared to the typical outdoor intensities. The intention was therefore to carry out relative comparisons of the species under the same conditions, rather than extrapolate directly to field conditions. There was no function for the growth cabinets to generate wind, but a vertical air flow of $0.2 \mathrm{~m} \mathrm{~s}^{-1}$ within the cabinet was provided by the air circulation system. Internal $\mathrm{T}$ and $\mathrm{RH}$ were recorded every minute by the cabinets' inbuilt logging systems.

T and RH settings for each of the trials (hereafter referred to as 'warm', 'hot', 'cool', 'dry' and 'humid') were chosen to represent a range of potential summertime $\mathrm{T} / \mathrm{RH}$ conditions that could be experienced in the southern UK. Actual T and RH recorded in the cabinets during each trial are presented in Table 1.

\section{Experimental procedure}

At the start of each trial, all containers were watered to container capacity by submerging in water for $15 \mathrm{~min}$ and then leaving to drain for $1 \mathrm{~h}$. Each container was then weighed and two SMC measurements per container were made before randomly placing all containers inside the CE cabinets. 'Saturated' SMCs of Salvia and Stachys were somewhat higher than other species in all trials, likely as a result of differing root densities affecting the water-holding capacity of the substrate; however, all
Table 1 Average temperature (T) and relative humidity (RH) settings for each of the potential UK summertime scenarios measured inside the controlled environment cabinets during each trial, with calculated vapour pressure deficit (VPD)

\begin{tabular}{lllll}
\hline Trial & \multicolumn{2}{l}{ Temperature $\left({ }^{\circ} \mathrm{C}\right)$} & Relative Humidity $(\%)$ & $\begin{array}{l}\text { Vapour Pressure } \\
\text { Deficit }(\mathrm{kPa})\end{array}$ \\
\cline { 2 - 3 } & Day & Night & & \\
\hline 'Warm' & 22 & 15 & 63 & 0.94 \\
'Hot' & 26 & 17 & 58 & 1.34 \\
'Cool' & 16 & 10 & 75 & 0.53 \\
'Dry' & 22 & 15 & 42 & 1.33 \\
'Humid' & 21 & 14 & 79 & 0.55 \\
\hline
\end{tabular}

containers were watered to container capacity and SMCs were all within the well-watered range previously identified for this substrate $\left(>0.250 \mathrm{~m}^{3} \mathrm{~m}^{-3}\right)$. Three containers of each species/control were placed in each $\mathrm{CE}$ cabinet. Containers remained in the cabinets for the remainder of the trial, and were removed every $24 \mathrm{~h}$ for weighing and SMC measurement. Daily ET was taken to be the weight loss per container in each 24-h period, and the proportion of total ET accounted for by plant transpiration (i.e. if $\mathrm{ET}=100 \%$ and evaporation from bare substrate $=40 \%$ of ET, then plant transpiration $=60 \%$ of total ET) was calculated for each species.

To ensure survival of all plants and avoid irreversible damage, trials were ended when the SMC of any species fell below $0.100 \mathrm{~m}^{3} \mathrm{~m}^{-3}$ (i.e. after 4-5 days). Containers were then removed from the cabinets and placed in a glasshouse where they were watered daily and allowed to recover for at least three days before the start of the next trial. Plant size (height and diameter) was also measured at the start of every trial, and, once all trials were complete, four plants per species were harvested for leaf area measurement.

\section{Statistical analysis}

All statistical analysis was carried out using GenStat 16th edition software (VSN International Ltd., Hemel Hempstead, UK). Analysis of variance (ANOVA) was used in both experiments to assess the effect of species choice on various parameters. Normality assumptions and variance levels were checked for homogeneity and variables were reported as a mean for each treatment with associated Least Significant Difference (LSD), which was used to assess significant differences between treatments at 5\% significance level. In Experiment 1, linear regressions were also carried out to test the relationship between the amount of water retained on the 'canopy/substrate complex' and antecedent SMC, ET prior to rainfall application, and various plant/canopy parameters. 


\section{Results}

\section{Experiment 1: The effect of vegetation type on green roofs' capacity to capture rainfall}

The proportion of rainfall retained on the plant canopy in 'saturated' conditions varied significantly between species (Fig. 3). Sedum and Stachys retained the most water (17.1 and 13.1\% of the total rainfall respectively) whilst Heuchera retained the least rainfall (2.2\%) and was similar to the unvegetated control. Even when retention was expressed relative to leaf area to account for varying canopy size, Sedum retained most rainfall on the canopy and both Sedum and Stachys retained more than Heuchera (data not shown). Retention on the canopy correlated significantly with leaf area density $\left(\mathrm{R}^{2}=0.54 ; P<0.001\right)$, shoot dry weight $\left(\mathrm{R}^{2}=0.72 ; \mathrm{P}<0.001\right)$ and canopy height $\left(\mathrm{R}^{2}=0.48 ; \mathrm{P}<0.001\right)$ (data not shown).

Total ET in the 72-h dry period between rainfall applications varied significantly between species/control (Fig. 4A), with Salvia and Stachys trays losing significantly more water than Sedum and the bare substrate. In this experiment, Heuchera trays had very low ET, similar to the bare substrate, with a loss of just $5.9 \mathrm{~mm}$ in $72 \mathrm{~h}$. However, when expressed per unit leaf area to account for differing canopy sizes, ET with Heuchera was similar to Salvia and Stachys, whilst water uptake by Sedum was significantly lower (data not shown).

Rainfall retention on the whole 'canopy/substrate complex' was much higher in 'unsaturated' conditions (i.e. following a 72-h antecedent dry period; Fig. 4B), and was strongly correlated with total $\mathrm{ET}$ in the preceding $72 \mathrm{~h}\left(\mathrm{R}^{2}=0.94 ; \mathrm{P}<0.001\right.$; data not shown). Retention varied significantly between treatments, with Stachys (72.9\%) and Salvia (63.6\%) retaining significantly more rainfall than all other species and over 3 times more than the bare substrate (20.5\%). Retention with Stachys was also 2.5 times greater than with Heuchera, which retained a relatively small proportion of the rainfall $(28.5 \%)$, similar to the bare substrate.

\section{Experiment 2: The impact of varying temperature and humidity on plants' water use}

Daily ET rates varied significantly between treatments, and differences in cumulative ET between treatments became greater over time. Cumulative ET in $96 \mathrm{~h}$ was significantly different between treatments in all T/RH conditions (Fig. 5), with the same pattern evident in all simulated scenarios: Stachys and Salvia had the highest ET, followed by Heuchera and then Sedum, whilst the bare substrate had the lowest ET in all trials. Accounting for plant size, relative water loss per unit leaf area was similar for the three broadleaf species, whilst Sedum was always lower (data not shown).

For every species, there were also significant differences in ET among T/RH treatments. Cumulative ET in the 'hot' and 'dry' treatments (i.e. high VPD) was always significantly greater than in the 'cool' and 'humid' treatments (i.e. low VPD) with all species. ET from the bare substrate was particularly low in the 'cool' and 'humid' treatments, around 3.5 times lower than with Stachys compared to 2.5 times lower in the 'warm', 'hot' and 'dry' treatments. This was also evident from the proportion of total ET in $96 \mathrm{~h}$ accounted for by plant transpiration, which was highest in the 'cool' and 'humid' treatments for all species (Table 2).

Daily ET of all species declined after Day 1 in all T/RH treatments, concurrently with a decline in SMC. Similar patterns of decline were observed in all trials, but were typically greater in the 'hot' and 'dry' treatments and slower in the 'cool' and 'humid' treatments for all species/control. Daily ET in the 'warm' treatment, with associated SMCs (Fig. 6), is shown here as a representative of the average ET decline
Fig. 3 Mean rainfall retention on the canopy in 'saturated' conditions. Data (bars) are means of 6 replicate trays per treatment, with associated standard error of the mean (SEM) and least significant difference between means (LSD, 5\%, shown as a vertical line in the upper left of the Figure); different letters indicate statistically significant differences between treatments

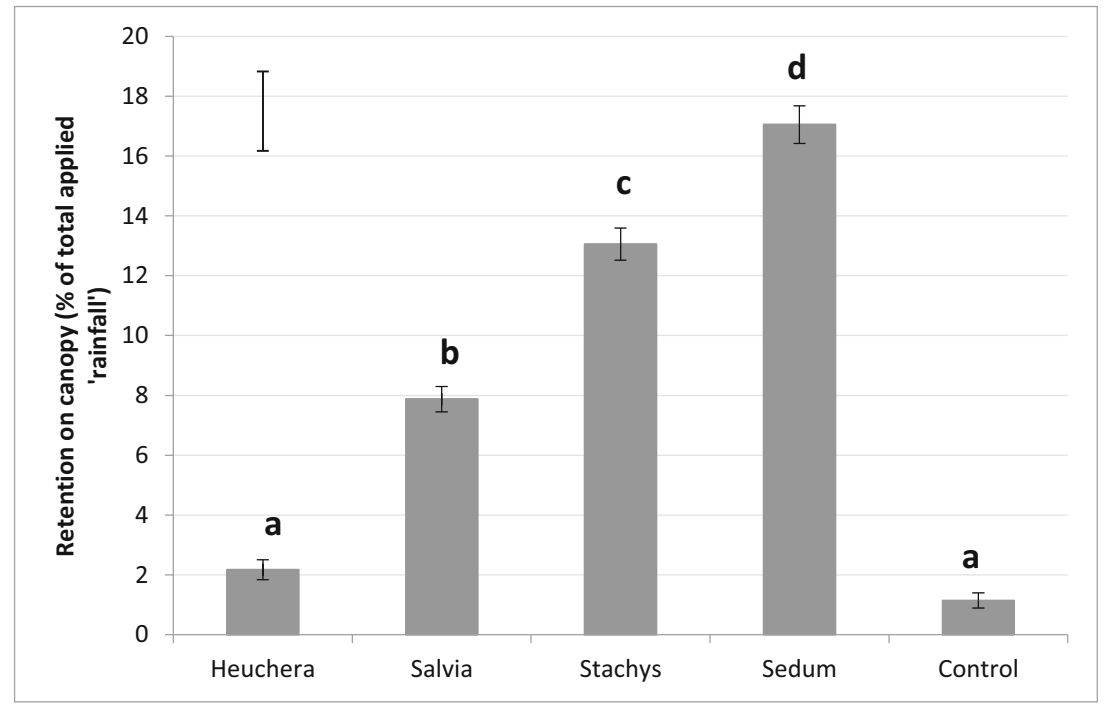


Fig. 4 Mean cumulative evapotranspiration (ET) from each tray for $72 \mathrm{~h}$ following saturation (A) and mean rainfall retention on the 'canopy/substrate complex' in 'unsaturated' conditions (i.e. following the $72-\mathrm{h}$ antecedent dry period) (B). Data are means of 6 replicate trays per treatment, with associated standard error of the mean (SEM) and least significant differences between means (LSD, 5\%, shown as vertical lines above the line graph); different letters on Fig. 4B indicate statistically significant differences between treatments
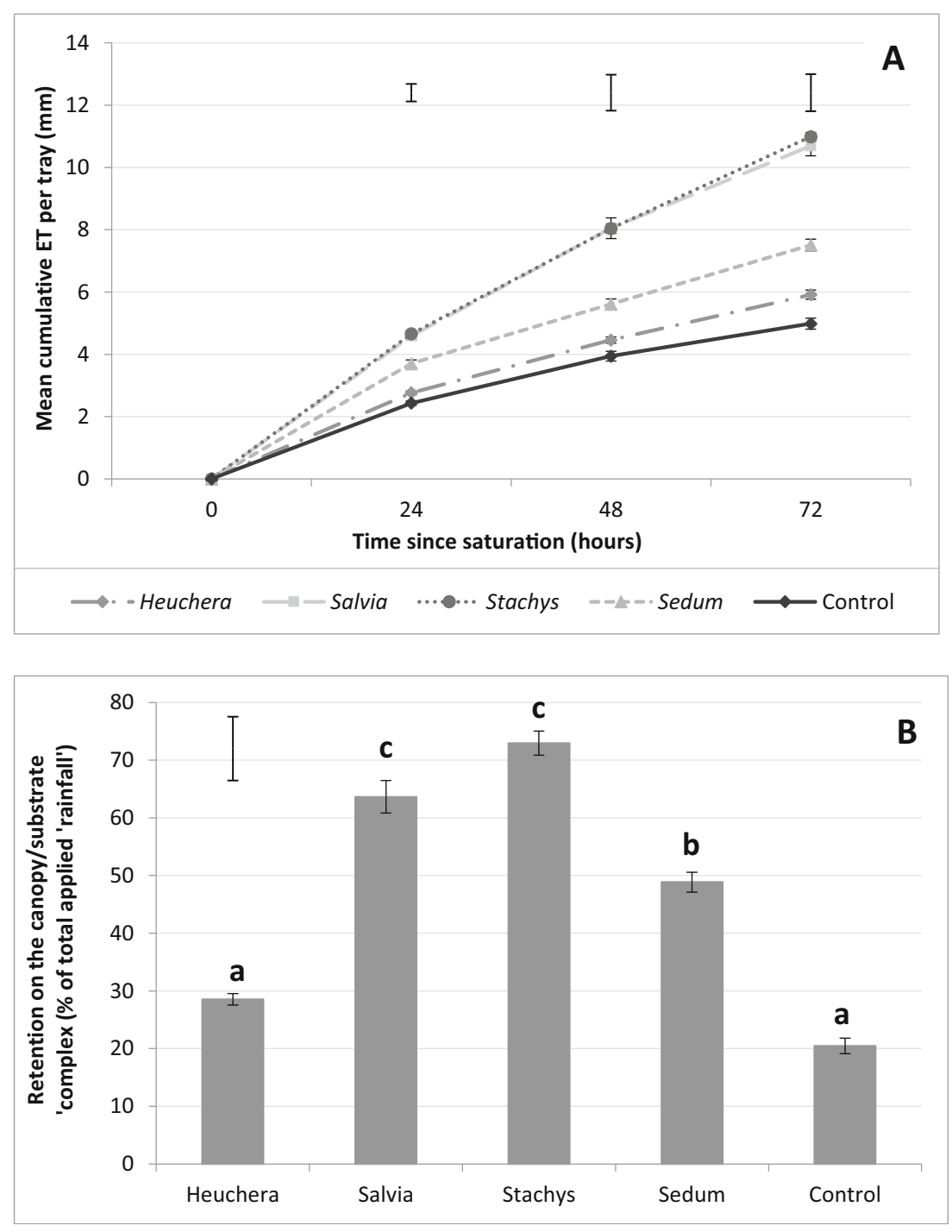

Fig. 5 Mean cumulative evapotranspiration (ET) per container in $96 \mathrm{~h}$ in each temperature/relative humidity (T/RH) treatment. Data are means of 6 replicates per species/control with associated standard error of the mean (SEM) and least significant difference between means (LSD, 5\%, shown as vertical lines above the bars)

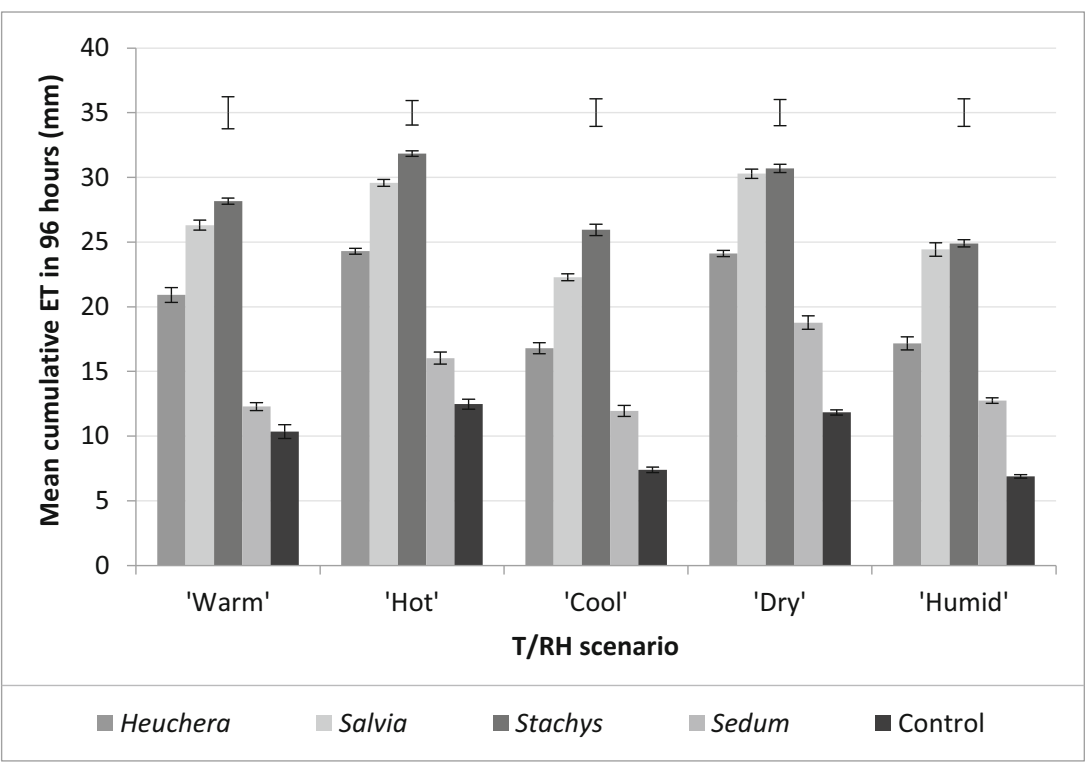


Table 2 Contribution of transpiration (\%) to total ET after $96 \mathrm{~h}$ in each of the T/RH treatments. Data are means of 6 replicates per treatment

\begin{tabular}{|c|c|c|c|c|c|}
\hline \multirow[t]{2}{*}{ Species } & \multicolumn{5}{|c|}{ Contribution of transpiration to total ET in each T/RH treatment (\%) } \\
\hline & 'Warm' & 'Hot' & ‘Cool’ & 'Dry' & 'Humid' \\
\hline Heuchera & 51 & 49 & 56 & 51 & 60 \\
\hline Salvia & 61 & 58 & 67 & 61 & 72 \\
\hline Stachys & 63 & 61 & 72 & 61 & 72 \\
\hline Sedum & 16 & 22 & 38 & 37 & 46 \\
\hline
\end{tabular}

observed among all studied treatments. With Stachys, the decline in daily ET was initially rapid, reducing by around $4 \mathrm{~mm}$ day $^{-1}$ each day in the 'warm' treatment (from $12.36 \mathrm{~mm} \mathrm{day}^{-1}$ on Day 1 to $4.31 \mathrm{~mm} \mathrm{day}^{-1}$ on Day 3; Fig. 6a), before appearing to slow, decreasing by only $1.32 \mathrm{~mm}^{-1}$ day $^{-1}$ on Day 4. Stachys SMC also declined rapidly in the first 3 days, from $0.548 \mathrm{~m}^{3} \mathrm{~m}^{-3}$ when 'saturated' to
$0.158 \mathrm{~m}^{3} \mathrm{~m}^{-3}$ after 3 days of drying (Fig. 6b). Stachys ET was initially significantly higher than all other species but declined to such an extent that by Day 3 it was significantly lower than Salvia and by Day 4 it was similar to Sedum. The declines in both daily ET and SMC were much slower with Sedum and the bare substrate, with daily ET for both reducing by only $1.17 \mathrm{~mm} \mathrm{day}^{-1}$ from Day 1 to Day 4 .
Fig. 6 Average daily ET per container in the 'warm' treatment (a) and associated average substrate moisture content (SMC) of each treatment at the start of each 24-h period (b). Data are means of 6 replicates per treatment with associated standard error of the mean (SEM) and least significant differences between means (LSD, 5\%, shown as vertical lines above the bars in $6 \mathrm{~A})$
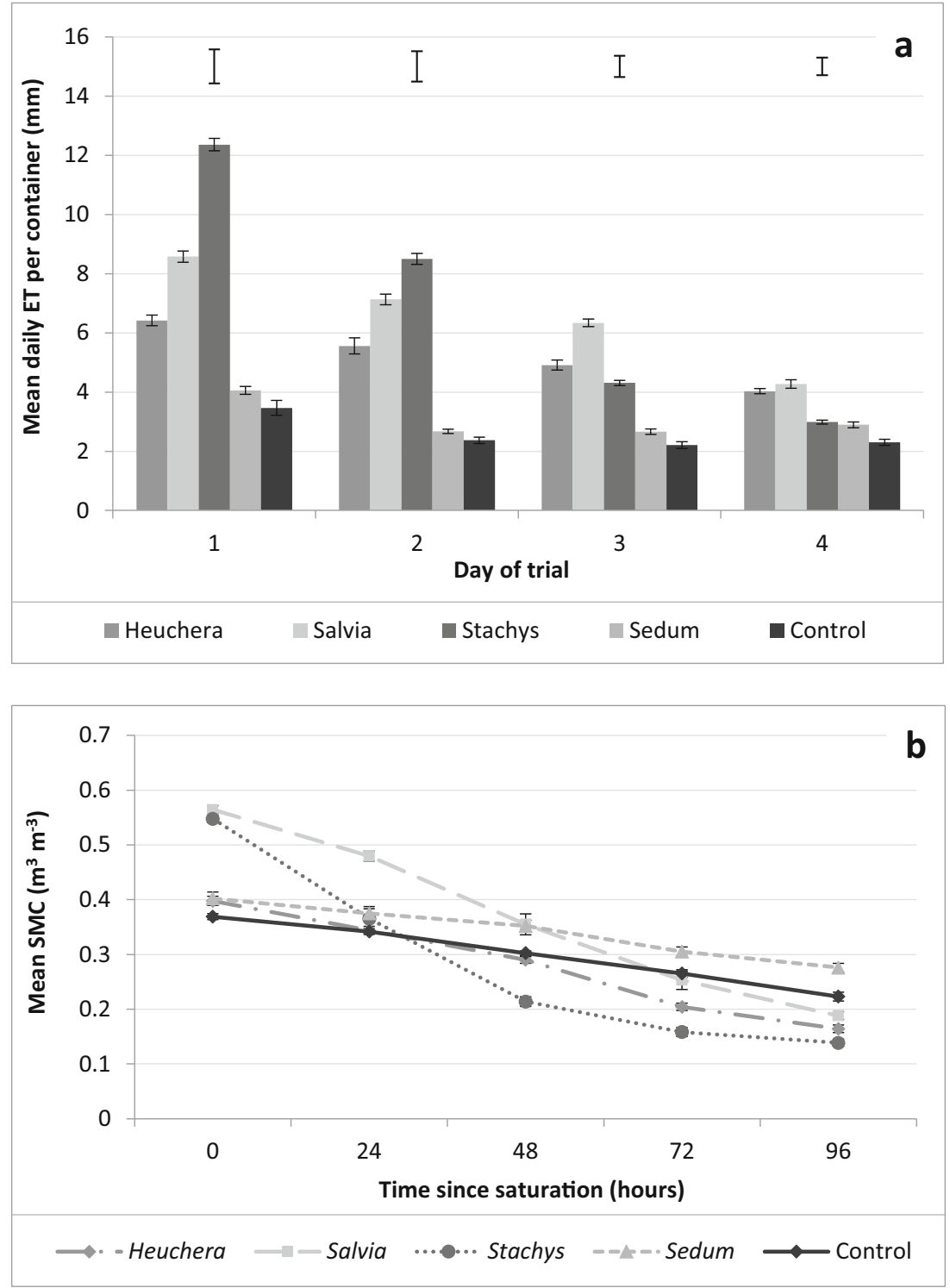


\section{Discussion}

Our paper approaches the question of runoff reduction from a biological perspective. In the literature thus far, there is no detailed experimental assessment of the plant/ biological mechanisms which underlie better performance (or otherwise) of some plants over others. Our aim was therefore to establish what are the driving factors linked with good rainfall retention performance of plants and consequent runoff reduction. We acknowledge that differences in local environmental and edaphic conditions (most importantly temperature, wind, substrate depth and type) will also impact on the extent of runoff reduction. We therefore focus on relative comparisons between plant species to give us a generalised idea of order of magnitude of difference between species in the capacity for runoff reduction.

\section{Contribution of canopy interception to rainfall retention}

We observed significant species differences in rainfall retention on the canopy in 'saturated' conditions, with Sedum retaining the most rain $(17.1 \%)$, followed by Stachys (13.1\%) and Salvia (7.9\%), whilst Heuchera retained the least (2.2\%). In an earlier study, Nagase and Dunnett (2012) identified plant characteristics such as canopy height, diameter and density, and waxy or hairy leaves as factors that may affect the amount of rainfall retained on vegetation. In our experiment, rainfall retention on the canopy was significantly correlated with shoot dry weight and leaf area density, confirming that species with large and/or dense canopies are able to retain the most rainfall and thus maximise stormwater management provision. Sedum in particular formed a very dense canopy, despite having one of the smallest canopies in terms of leaf area, height and diameter, with stems accounting for up to $20 \%$ of the total canopy area in addition to leaf area. As well as having full, dense canopies, the hairy leaves of Salvia and especially Stachys were able to efficiently retain water droplets on their surfaces, even when droplets coalesced and became large, resulting in high rainfall retention on the canopy. In contrast, rainfall retention on the Heuchera canopy was low; the smooth, horizontally-aligned Heuchera leaves tended to form an almost continual canopy layer that 'raindrops' bounced off and dripped, preventing water from infiltrating through the canopy to the substrate or being retained on the leaves. Indeed, up to $20 \%$ of the total applied rainfall dripped off the Heuchera canopy in a preliminary study with individual plants (Kemp 2018). A large proportion of rainfall dripping off from the vegetation onto surrounding surfaces in this way would result in lower retention on a green roof (due to quicker substrate saturation and less canopy retention), thus potentially limiting the ability of a roof planted with Heuchera to provide effective stormwater management. It would also be more of an issue on roofs where the substrate is already saturated after a rainfall. Obviously though, as canopy grows over time, the capacity for retention will change, and possibly at different rates in different species depending on their growth rates. Our intention here was predominantly to highlight the canopy properties (density, small leaf size, hairiness) which appear to correlate with better canopy retention.

Overall however, contribution of the canopy to rainfall retention was smaller compared to the contribution of ET and substrate water storage. MacIvor and Lundholm (2011) found that vegetated treatments only retained up to $4 \%$ more than bare substrate, depending on species. Although relatively small, this additional retention provided by the canopy would be important at times when antecedent SMC is high at the onset of rainfall, for example, when storms occur close together and there is little time for restoration of substrate retention capacity between rainfall events, or during cooler and wetter weather or seasons when ET is limited. In these situations, canopy interception may be the sole mechanism for retention, and so having a species capable of high canopy retention is essential. In our experiment, canopy characteristics were particularly important in 'cool' and 'humid' weather scenarios when antecedent substrate moisture was high, with large, dense canopies (Sedum) providing the greatest rainfall retention. However, restoration of the canopy's capacity (via evaporation) to retain further rainfall would be influenced by microclimatic conditions (wind speed, temperature, $\mathrm{RH}$ ), and by the structure/configuration of the canopy.

\section{Contribution of ET to rainfall retention}

Removal of moisture from the substrate through ET between storms restores the retention capacity of the substrate for rainfall retention in subsequent storms. This is generally considered to be a more important mechanism than canopy interception for stormwater management provision (Stovin et al. 2015) since it is clear that the substrate itself represents the majority of a green roof's water storage (Dunnett et al. 2008; VanWoert et al. 2005). Varying ET rates of different species could therefore determine the extent and speed of substrate retention capacity recharge, and thus overall rainfall retention performance. Indeed, rainfall retention was strongly correlated with ET in the preceding 72-h dry period $\left(\mathrm{R}^{2}=0.94 ; P<0.001\right)$, thus confirming the importance of ET as a key factor determining a green roof's retention performance (Stovin et al. 2012). The different ET rates of each species and bare substrate in the 72-h dry period preceding rainfall application in 'unsaturated' conditions resulted in significantly different antecedent SMCs at the onset of rainfall. Greater substrate storage was therefore available with the species with high ET rates (and thus low antecedent SMCs), and rainfall retention was consequently greater with these species $(72.9$ and $63.6 \%$ for the high-performing Stachys and Salvia respectively) 
compared to those with low ET rates (48.9 and $20.5 \%$ for lower performing Sedum and bare substrate, respectively). These results clearly demonstrate the impact of varying ET rates between species on their ability to restore the substrate's water retention capacity and thus retain rainfall. This highlights the potential to maximise stormwater management provision on a green roof by selecting species with high ET rates, such as Stachys and Salvia, particularly in the context of mild, temperate climates such as UK. Some recent research suggests however that drought-avoiding, low water-use plants, can also support rainfall retention on green roofs (Szota et al. 2017; Lundholm et al. 2010) and they have a role in climates with lower summer rainfall and higher temperatures.

The ability of succulent species such as Sedum to provide stormwater management is often considered to be limited by their low ET rates (Nagase and Dunnett 2012), resulting in slow restoration of substrate retention capacity. In our study, however, the ET rates of all vegetated treatments, including Sedum, were significantly higher than from bare substrate, in all T/RH treatments. The proportion of total cumulative ET in $96 \mathrm{~h}$ provided by plant transpiration was large, particularly for the broadleaf species (e.g. up to $72 \%$ for Salvia and Stachys and $60 \%$ for Heuchera) and even for Sedum - up to $46 \%$. This clearly demonstrates that the presence of any vegetation on a green roof enables greater restoration of substrate retention capacity, and thus greater rainfall retention, than bare substrate alone. Indeed, several other studies have reported significantly greater rainfall retention with vegetated treatments compared to bare substrate (e.g. Volder and Dvorak 2014; Beecham and Razzaghmanesh 2015; Stovin et al. 2015).

\section{Rainfall retention in various summertime temperature and relative humidity scenarios}

The 'ranking' of plant species in terms of both daily and cumulative ET (and thus their potential to reduce runoff), was always the same in all T/RH scenarios, with Stachys and Salvia always having significantly higher ET than all other species/control, Heuchera ET significantly greater than Sedum, and bare substrate ET significantly lower than all species. These results suggest that maximum stormwater management provision would therefore always be achieved with high ET species Stachys and Salvia, regardless of the predominant summertime weather conditions. Indeed, the same 'ranking' of species was identified in one of our earlier outdoor experiments when stomatal conductance $\left(g_{s}\right)$ was measured as an indicator of ET and cooling capacity, with Stachys and Salvia having the greatest $g_{s}$ and Sedum the lowest (Vaz Monteiro et al. 2017). Poë et al. (2015) also observed lower ET rates with Sedum compared to herbaceous species in a controlled environment study. In our study, Stachys and Salvia took up approximately twice as much water from the substrate in $72 \mathrm{~h}$ than all other species/control, thus theoretically doubling the available substrate retention capacity for a subsequent rainfall event.

As well as varying between species, ET rates of all species/ control were significantly higher in treatments with high VPD ('hot' and 'dry') compared to low VPD treatments ('cool' and 'humid'). Indeed, total cumulative ET in $96 \mathrm{~h}$ ranged from $6.89 \mathrm{~mm}$ (bare substrate; 'humid' treatment) to $31.83 \mathrm{~mm}$ (Stachys; 'hot' treatment), meaning that more substrate storage capacity could be created on hot, dry days. Moreover, for all species, the contribution of plant transpiration to total ET was particularly large in the T/RH treatments with low VPD ('cool' and 'humid'), likely due to limited evaporation from the bare substrate and a more abundant water supply (i.e. higher SMC) in vegetated treatments in these conditions (Voyde et al. 2010b).

For ET to continue at its maximum potential rate, water must be continually supplied to the evaporating surfaces (i.e. the substrate or leaf surfaces; Verhoef and Egea 2013). As SMC declines over time after wetting, the water supply to the evaporating surfaces becomes increasingly restricted, causing ET rates to fall (Stovin et al. 2013). This was clearly observed in all $\mathrm{T} / \mathrm{RH}$ treatments in Experiment 2, with daily ET declining concurrently with SMC. This decline was particularly rapid in high VPD treatments ('hot' and 'dry') and for the species with high ET rates (i.e. Stachys and Salvia), which quickly depleted substrate moisture. Indeed, daily ET with Stachys declined rapidly in the first 3 days after saturation, (e.g. from 12.36 day $^{-1}$ on Day 1 to $4.31 \mathrm{~mm}^{-1}$ day $^{-1}$ on Day 3 in the 'warm' trial), likely as a result of reduced availability of substrate moisture (SMC declined from 0.548 to $0.158 \mathrm{~m}^{3} \mathrm{~m}^{-3}$ over the same period). Consequently, by Day 3 Stachys ET was significantly lower than Heuchera and Salvia ET and similar to Sedum ET, and by the end of all T/RH trials, the daily ET of Stachys was approaching that of the bare substrate. These results imply that the advantage of species with high ET rates (e.g. Stachys) over species with lower ET rates (e.g. Sedum), in terms of rate of restoration of substrate retention capacity, would be greatest in the first 2 3 days following rainfall. In our experience, in previous field experiments on the same plant species carried over several years in the temperate climate of the UK's south-east (Vaz Monteiro et al. 2017; Blanusa et al. 2013), substrate depth of $10 \mathrm{~cm}$ was sufficient to sustain the plants chosen in this study without the frequent need for supplementary irrigation. In the prolonged absence of natural rainfall, supplementary irrigation should be applied to prevent substrate moisture deficit. Since ET has previously been shown to be the primary mechanism by which these species provide cooling (Vaz Monteiro et al. 2017), maintaining high ET rates with supplementary irrigation will also ensure that cooling provision is not compromised, so a green roof will be in a position to provide more efficiently two services (cooling and runoff reduction). Provision of supplementary irrigation obviously adds another 
layer of complexity and cost to green roof projects, and requires the support of horticultural specialists in reaching the right balance of most effective planting vs irrigation costs.

\section{Conclusions}

Plant canopies alone retained up to $17 \%$ (e.g. in most effective Sedum) of the total rainfall in this study, with Salvia and Stachys also retaining in excess of $10 \%$, and can make a substantial contribution to rainfall retention on a green roof. Rainfall retention was also strongly correlated with total ET in the preceding $72 \mathrm{~h}\left(\mathrm{R}^{2}=0.94 ; P<0.001\right)$. Therefore, species with high ET rates (Salvia and Stachys) were able to provide the greatest stormwater management service (up to $72 \%$ retention due to ET component vs $46 \%$ in low-ET Sedum). Furthermore, species 'rankings', in terms of ET and thus restoration of substrate retention capacity, were the same in all simulated potential UK summertime temperature and relative humidity scenarios, indicating that 'superior' species would be able to provide the greatest stormwater management provision in all climatic conditions. Although the ET rates are greatest in 'warm' and 'hot' conditions, the contribution of the plant transpirational component became particularly important in 'cool' and 'humid' conditions (with $T=16{ }^{\circ} \mathrm{C}$ and $\mathrm{RH}=80 \%)$. This is because the evaporation alone from the substrate was low in these circumstances, and transpiration by vegetation increased the substrate's storage capacity.

Acknowledgements This work was financially supported by a European Institute of Technology (EIT) 'Climate-KIC' PhD studentship. We are grateful to Paul Mealey at the RHS for constructing the rainfall simulator, and Matthew Richardson and Val Jasper at the University of Reading for technical help. We are also grateful to Dr. Ana Mijić, Prof Čedo Maksimović and the 'Blue Green Dream' team members at Imperial College, London for advice and stimulating discussions.

\section{Compliance with ethical standards}

Conflict of interest The authors have no conflicts of interest to declare.

Open Access This article is distributed under the terms of the Creative Commons Attribution 4.0 International License (http:// creativecommons.org/licenses/by/4.0/), which permits unrestricted use, distribution, and reproduction in any medium, provided you give appropriate credit to the original author(s) and the source, provide a link to the Creative Commons license, and indicate if changes were made.

\section{References}

Allen RG, Pereira LS, Raes D, Smith M (1998) Crop evapotranspirationguidelines for computing crop water requirements-FAO irrigation and drainage paper 56. vol 300. FAO, Rome
Aloisio JM, Tuininga AR, Lewis JD (2016) Crop species selection effects on stormwater runoff and edible biomass in an agricultural green roof microcosm. Ecol Eng 88:20-27. https://doi.org/10.1016/j. ecoleng.2015.12.022

Anon (2013) 2011 Census: characteristics of built-up areas. Office of National Statistics

Beecham S, Razzaghmanesh M (2015) Water quality and quantity investigation of green roofs in a dry climate. Water Res 70:370-384. https://doi.org/10.1016/j.watres.2014.12.015

Berretta C, Poë S, Stovin V (2014) Moisture content behaviour in extensive green roofs during dry periods: the influence of vegetation and substrate characteristics. J Hydrol 511:374-386

Blanusa T, Vaz Monteiro MM, Fantozzi F, Vysini E, Li Y, Cameron RWF (2013) Alternatives to Sedum on green roofs: can broad leaf perennial plants offer better 'cooling service'? Build Environ 59:99-106. https://doi.org/10.1016/j.buildenv.2012.08.011

Brandão C, Cameira MR, Valente F, Cruz de Carvalho R, Paço TA (2017) Wet season hydrological performance of green roofs using native species under Mediterranean climate. Ecol Eng 102:596-611. https://doi.org/10.1016/j.ecoleng.2017.02.025

Butler D, Davies J (2003) Urban drainage. Taylor \& Francis, London

Carter TL, Rasmussen TC (2006) Hydrologic behavior of vegetated roofs. J Am Water Resour Assoc 42(5):1261-1274

Dunnett N, Nagase A, Booth R, Grime P (2008) Influence of vegetation composition on runoff in two simulated green roof experiments. Urban Ecosyst 11(4):385-398

Elliott RM, Gibson R, Carson TB, Marasco D, Culligan PJ, McGillis WR (2016) Green roof seasonal variation: comparison of the hydrologic behavior of a thick and a thin extensive system in new York City. Environ Res Lett 11(7):074020

Getter KL, Rowe DB, Andresen JA (2007) Quantifying the effect of slope on extensive green roof stormwater retention. Ecol Eng 31(4):225231. https://doi.org/10.1016/j.ecoleng.2007.06.004

Iserloh T, Fister W, Seeger M, Willger H, Ries JB (2012) A small portable rainfall simulator for reproducible experiments on soil erosion. Soil Tillage Res 124:131-137. https://doi.org/10.1016/ j.still.2012.05.016

Kemp S (2018) Impact of plant choice and water management on the provision of ecosystem services by green roofs. University of Reading

Lundholm J, MacIvor JS, MacDougall Z, Ranalli M (2010) Plant species and functional group combinations affect green roof ecosystem functions. PLoS One 5(3):e9677

MacIvor JS, Lundholm J (2011) Performance evaluation of native plants suited to extensive green roof conditions in a maritime climate. Ecol Eng 37(3):407-417. https://doi.org/10.1016/j.ecoleng.2010.10.004

Mentens J, Raes D, Hermy M (2006) Green roofs as a tool for solving the rainwater runoff problem in the urbanized 21 st century? Landsc Urban Plan 77(3):217-226

Met Office (2017) UK Climate: https://www.metoffice.gov.uk/public/ weather/climate/. Accessed 4th October 2017

Nagase A, Dunnett N (2012) Amount of water runoff from different vegetation types on extensive green roofs: effects of plant species, diversity and plant structure. Landsc Urban Plan 104(3-4):356-363. https://doi.org/10.1016/j.landurbplan.2011.11.001

Perry T, Nawaz R (2008) An investigation into the extent and impacts of hard surfacing of domestic gardens in an area of Leeds, United Kingdom. Landsc Urban Plan 86(1):1-13

Poë S, Stovin V, Berretta C (2015) Parameters influencing the regeneration of a green roof's retention capacity via evapotranspiration. J Hydrol 523:356-367

Raimondo F, Trifilò P, Lo Gullo MA, Andri S, Savi T, Nardini A (2015) Plant performance on Mediterranean green roofs: interaction of species-specific hydraulic strategies and substrate water relations. AoB Plants 7. https://doi.org/10.1093/aobpla/plv007 
Rayner JP, Farrell C, Raynor KJ, Murphy SM, Williams NSG (2016) Plant establishment on a green roof under extreme hot and dry conditions: the importance of leaf succulence in plant selection. Urban For Urban Green 15:6-14. https://doi.org/10.1016/j.ufug.2015.11.004

Sims AW, Robinson CE, Smart CC, Voogt JA, Hay GJ, Lundholm JT, Powers B, O'Carroll DM (2016) Retention performance of green roofs in three different climate regions. J Hydrol 542:115-124. https://doi.org/10.1016/j.jhydrol.2016.08.055

Soulis KX, Ntoulas N, Nektarios PA, Kargas G (2017) Runoff reduction from extensive green roofs having different substrate depth and plant cover. Ecol Eng 102:80-89. https://doi.org/10. 1016/j.ecoleng.2017.01.031

Speak A, Rothwell J, Lindley S, Smith C (2013) Rainwater runoff retention on an aged intensive green roof. Sci Total Environ 461:28-38

Starry O, Lea-Cox J, Ristvey A, Cohan S (2016) Parameterizing a waterbalance model for predicting stormwater runoff from green roofs. J Hydrol Eng 21(12):04016046

Stovin V, Vesuviano G, Kasmin H (2012) The hydrological performance of a green roof test bed under UK climatic conditions. J Hydrol 414: $148-161$

Stovin V, Poë S, Berretta C (2013) A modelling study of long term green roof retention performance. J Environ Manag 131:206-215. https:// doi.org/10.1016/j.jenvman.2013.09.026

Stovin V, Poë S, De-Ville S, Berretta C (2015) The influence of substrate and vegetation configuration on green roof hydrological performance. Ecol Eng 85:159-172

Szota C, Farrell C, Williams NS, Arndt SK, Fletcher TD (2017) Droughtavoiding plants with low water use can achieve high rainfall retention without jeopardising survival on green roofs. Sci Total Environ 603:340-351
VanWoert ND, Rowe DB, Andresen JA, Rugh CL, Fernandez RT, Xiao L (2005) Green roof stormwater retention. J Environ Qual 34(3): 1036-1044

Vaz Monteiro M, Blanuša T, Verhoef A, Richardson M, Hadley P, Cameron RWF (2017) Functional green roofs: importance of plant choice in maximising summertime environmental cooling and substrate insulation potential. Energ Buildings 141:56-68. https://doi. org/10.1016/j.enbuild.2017.02.011

Verhoef A, Egea G (2013) Soil water and its management. In: Gregory PJ, Nortcliff S (eds) Soil conditions and plant growth. Blackwell Publishing Ltd, Oxford, pp 269-322. https://doi.org/10.1002/ 9781118337295.ch9

Volder A, Dvorak B (2014) Event size, substrate water content and vegetation affect storm water retention efficiency of an un-irrigated extensive green roof system in Central Texas. Sustain Cities Soc 10:59-64. https://doi.org/10.1016/j.scs.2013.05.005

Voyde E, Fassman E, Simcock R (2010a) Hydrology of an extensive living roof under sub-tropical climate conditions in Auckland, New Zealand. J Hydrol 394(3-4):384-395. https://doi.org/10. 1016/j.jhydrol.2010.09.013

Voyde E, Fassman E, Simcock R, Wells J (2010b) Quantifying evapotranspiration rates for New Zealand green roofs. J Hydrol Eng 15(6): 395-403

Warhurst JR, Parks KE, McCulloch L, Hudson MD (2014) Front gardens to car parks: changes in garden permeability and effects on flood regulation. Sci Total Environ 485:329-339

Whittinghill LJ, Rowe DB, Andresen JA, Cregg BM (2015) Comparison of stormwater runoff from sedum, native prairie, and vegetable producing green roofs. Urban Ecosyst 18(1):13-29. https://doi.org/10. 1007/s11252-014-0386-8 